\title{
Mechanical Joining Utilizing Friction Stir Forming
}

\author{
Takahiro Ohshi ${ }^{1, a^{*}}$, Tadashi Nishihara ${ }^{1, b}$, and Hamed Mofidi Tabatabaei ${ }^{1, c}$ \\ ${ }^{1}$ School of Science and Engineering, Kokushikan University, 4-28-1 Setagaya, Setagaya-ku, \\ Tokyo 154-8515 Japan \\ atohashi@kokushikan.ac.jp, ㅁnisihara@kokushikan.ac.jp, cmofidi@kokushikan.ac.jp
}

Keywords: mechanical joining, friction stir welding, friction stir processing, friction stir forming, dissimilar materials

\begin{abstract}
The material ratio of steel in automobiles will likely decrease rapidly in the next decade with the advent of electric vehicles, which will promote the multi-materialization of parts. Hence, recently, researchers have successfully studied technologies for joining dissimilar materials. The authors have studied the joining of dissimilar materials by using the friction stir forming (FSF) approach. In the FSF process, a substrate material was first placed on a die. Next, friction stirring was conducted on the back surface of the material. The material then deformed and filled the cavity of the die because of high pressure and heat caused by the friction stirring. The authors utilized the FSF approach to generate mechanical joints between dissimilar materials. In this paper, the author introduces various techniques for joining dissimilar materials through FSF.
\end{abstract}

\section{Introduction}

The material ratio of normal steel in automobiles is expected to be rapidly reduced in next decade due to the use of high-specific-strength materials because of strict demand of lightweight parts. However, these materials tend to be expensive and have less energy absorption capacity in the event of car crush. Therefore, multilateralization of the automobile parts that are optimally designed with multiple materials including normal steel and high-specific-strength materials has been successfully promoted. Engineers in the automobile industry will eventually focus their attention on the methodology of dissimilar materials joining. Riveting has been utilized for dissimilar materials joining. The methodology delivers enough joint strength without considering the metallurgical condition of joined materials. However, it requires fasteners and increases the weight of the parts. Therefore, researchers are studying metallurgical joining methodologies without weight increase.

Friction stir welding (FSW) is a promising methodology for dissimilar materials joining. It was invented in the Welding Institute (TWI) in the UK in 1991 as a joining technique for aluminum members [1]. Linear FSW and friction stir spot welding(FSSW) with various dissimilar materials have now been studied extensively. Joining aluminum alloy and steel with FSW has begun to be employed for commercial cars [2]. For FSW and FSSW with aluminum alloy and steel $[3,4]$, the materials are successfully joined if process fulfills the following three conditions.

(1) A tool or stirred aluminum alloy scrapes the oxides and stains on the surface of the steel.

(2) A Fe-Al intermetallic compound (IMC) is successfully developed between the materials.

(3) The thickness of the IMC is controlled at less than $1 \mu \mathrm{m}$.

Because of the above conditions, the processing temperature and joined materials must be chosen carefully.

Additionally, some mechanical joining techniques fabricate a mechanical joint by employing plastic deformation of the joined materials without fasteners. For example, Abe et.al. [5] conducted mechanical clinching of zinc-aluminum alloy coated steel and aluminum alloy sheets. In this type of mechanical joining, materials can be chosen without regarding metallurgical restrictions. However, the dimensions of the materials, e.g. the thickness of the joined sheets, are sometimes restricted.

In this paper, we present a mechanical joining technique using plastic deformation of the joined materials and introduce its applications. We utilized friction stir processing as a metal-forming process to generate a mechanical joint instead of metallurgical solid-phase joining process. 


\section{Schematics of Joining}

Friction Stir Forming. Friction stir processing was originally invented as a solid bonding but now has applications that are more extensive. Thomas [6] reported embossing letters during FSW, which implied that friction stir processing could be applied to metal forming. Figure 1 illustrates the friction stir forming (FSF) invented by Nishihara $[7,8]$ in 2002. Friction stirring is conducted on a material plate on the die, and the material is then deformed to fill the cavity of the die under high pressure and heat caused by friction stirring. Consequently, the shape of the die is transferred to the material. Figures $2(\mathrm{a}-\mathrm{b})$ depict the example results of generating cylindrical extrusions on a $3 \mathrm{~mm}$-thick A5083 aluminum plate and a die with hole-cavities [9]. Thus, the materials in FSF often exhibit excellent deformability and moldability. Additionally, the height of the cylindrical extrusions in Fig. 2(a) was greater than that in Fig. 2(b) for smaller die-cavity holes but smaller for larger holes. These results imply that the two key factors to estimate the forming limit: the internal compression-force and softening of the material, and the volume of deformable material generated by the friction stirring. Figure 3 shows the volume of the generated extrusion. In spot FSF, the tool plunge force helps to increase compression-force inside the material; however, FSF with tool travel is more effective for collecting the deformable material volume generated by the friction stirring.

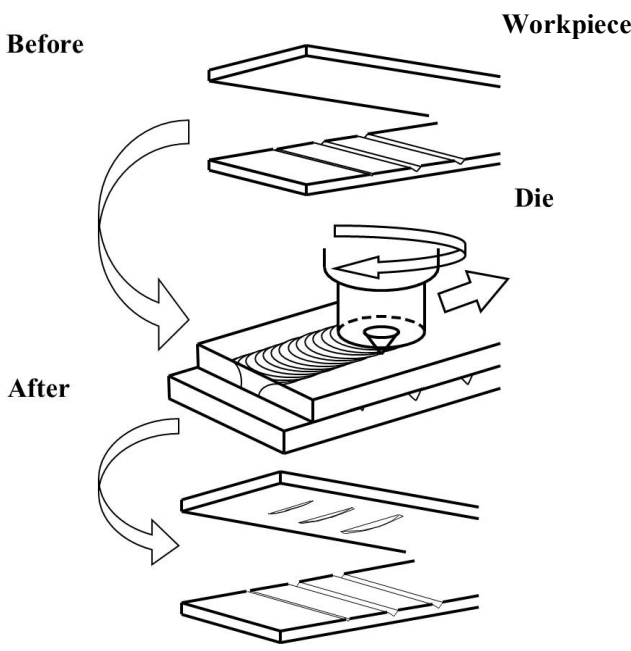

Fig. 1 FSF Schematics [8].

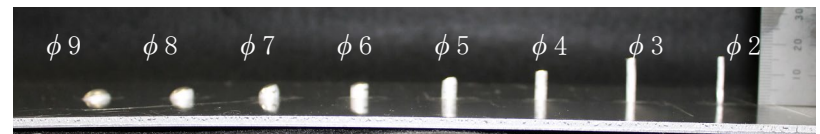

(a) Spot FSF

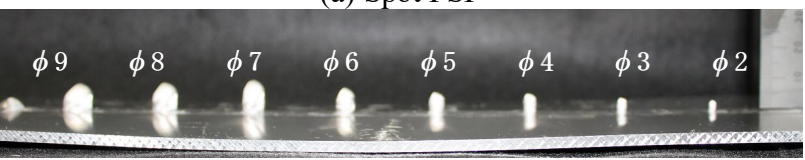

(b) FSF with tool travel

Fig. 2 Generation of cylindrical extrusions on a 3 mm-thick A5083 plate [9].

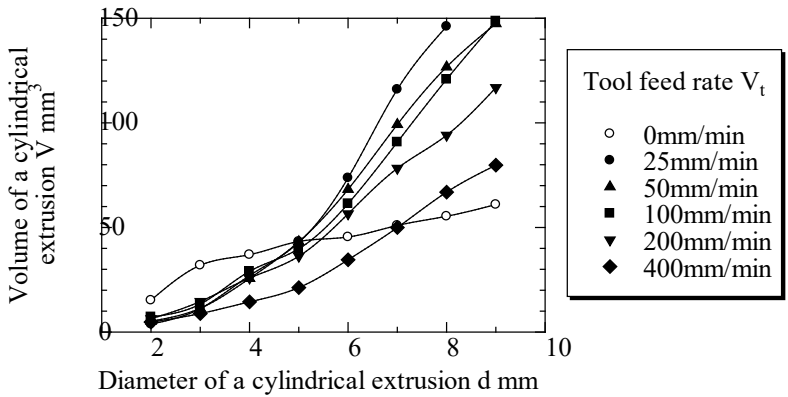

Fig. 3 Volume of cylindrical projections [9]. 
Mechanical Joining with Preprocessing to Generate an Interlocking Structure Source. Mechanical joining using FSF was conducted in the following steps: First, we fabricated a mechanical interlock source on a joined member during preprocessing, e.g. undercuts, inclined surfaces, and anchor structures. Second, the base material, such as an aluminum alloy plate, was placed on the joined member. Third, friction stir forming was conducted on the surface of the base material to enable the material to fill the source of the mechanical interlock because of the excellent moldability of the material during FSF. Finally, a mechanical joint between the joined member and the base material was generated. The above preprocessing can sometimes be combined with upstream processes such as press working and machining to manufacture joined parts.

\section{Applications}

Joining with Prepared Grooves. In the following examples, grooves generated with machining were utilized as a source of mechanical interlocking.

Cladding Dissimilar Material. Figure 4 illustrates the schematics of mechanical joining between an A6061 Aluminum alloy plate and a S45C steel bar. We prepared circular cross-sectional grooves on the surface of the steel bar and generated mechanical joints with FSF. Figure 5 depicts the product and dimensions of a joined steel bar[10]. Figure 6 plots the strength of the joint with single and multiple grooves. The number of grooves increases the strength of the joint, but the two parameters were not proportional because of uneven stress distribution in the longitudinal direction.

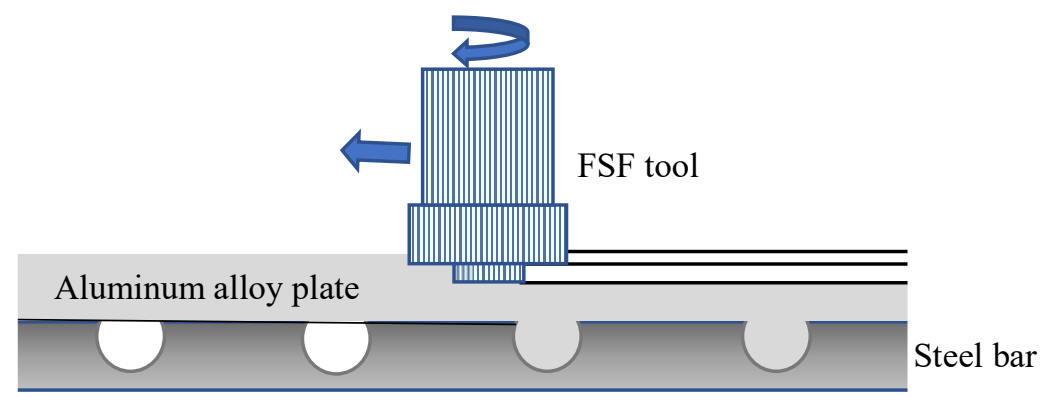

Fig. 4 Joining with prepared circular cross-sectional grooves.

(a)

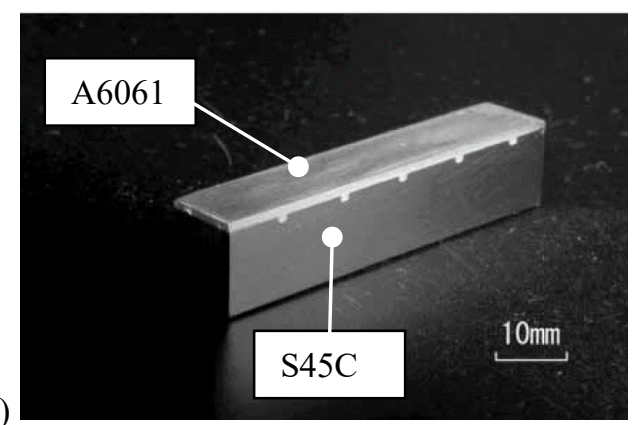

(b)

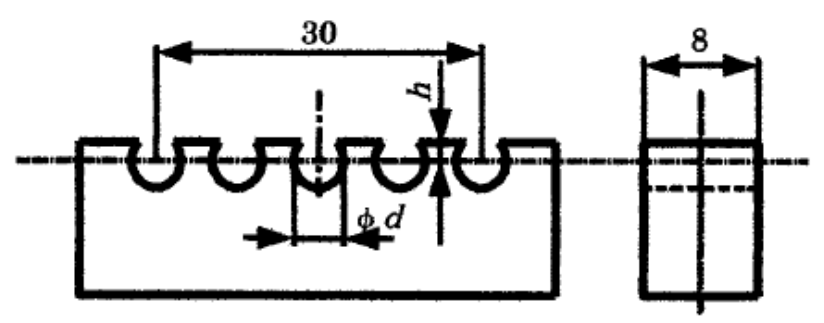

Fig. 5 Fabricated dissimilar material product [10]. (a) Photo, (b) Dimensions of the joined steel bar. 

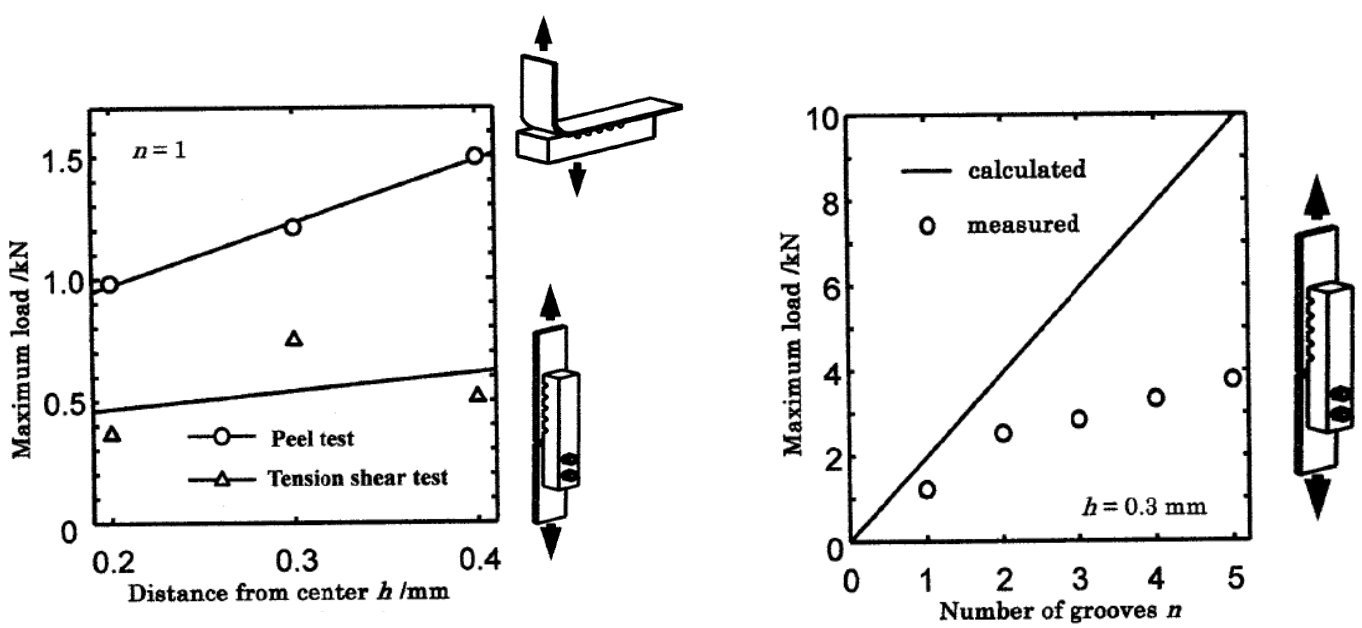

Fig. 6 Strength of the joint fabricated by FSF. [10]

Embedded Wire, Long Fibers, and Strands. Figure 7 illustrates the basic schematic for embedding a wire, long fibers, and strands[11]. First, we prepared a guide groove on the lower base material and added a wire. Second, we placed the upper base material over the lower base material and conducted friction stirring on the back surface. The upper base material fills the groove with FSF, and then the interface between the upper and lower base materials and shoulder of the groove was stirred and bonded as well as conventional FSW. However, the wire was pushed against the bottom the groove by the material flowing from the upper base metal without being stirred. With this methodology, wires, long fibers, and strands can be embedded in a material without stirring at lower temperature than that required for conventional fusion processes. Using superplastic material such as $\mathrm{Zn}-22 \mathrm{Al}$ further lowers processing temperature.

Figure 8 depicts an example product with a polyimide insulator wire embedded in copper. In this case, the processing temperature was controlled at less than $300^{\circ} \mathrm{C}$ to avoid damaging the polyimide cover. We also successfully embedded stainless steel strands in aluminum alloys (A2017, A2024, A5083, A6061, and A7075) [12].

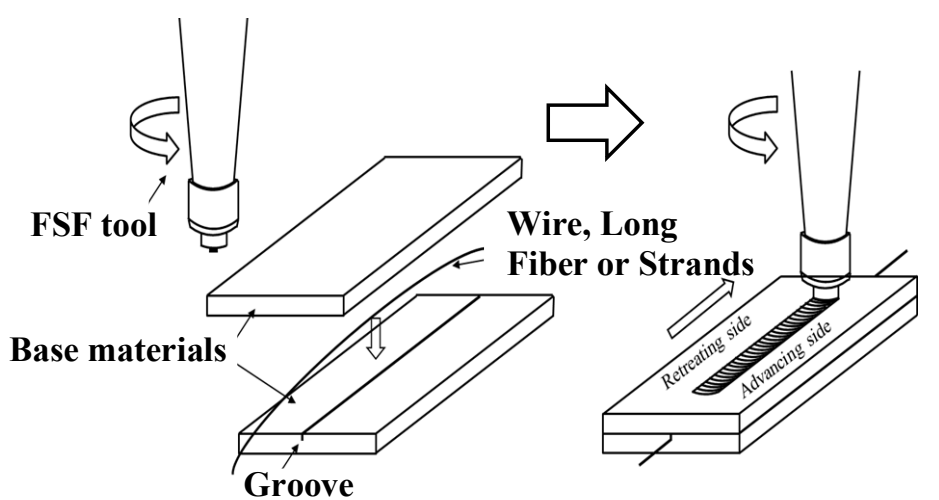

Fig. 7 Schematics of embedding a wire with FSF [11]. 
(a)

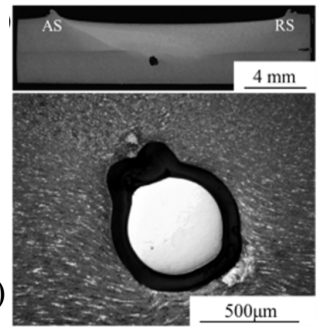

(b)

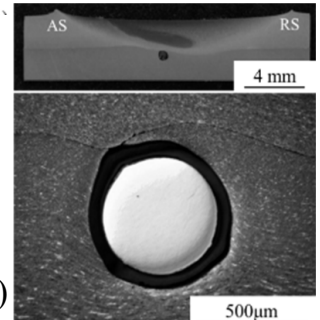

Fig. 8 Cross-sectional images of mechanically interlocked insulated copper wire formed by FSF for different process parameters. (a) Rotation speed of $440 \mathrm{rpm}$, travel speed of $50 \mathrm{~mm} / \mathrm{min}$.

(b) Rotation speed of $880 \mathrm{rpm}$, travel speed of $100 \mathrm{~mm} / \mathrm{min}$.

(AS advancing side, RS retreating side) [11].

Joining with Prepared Holes. In the following examples, prepared holes were utilized as a source of mechanical interlocking.

Fastenerless-Riveting. Figure 9 illustrates the schematics of fastener-less riveting by employing FSF [9]. First, a base material (host member) was placed on a joined member (i.e. a steel CFRP plate) with prepared holes. These members were put on a die with a cavity to fabricate the head of the rivetlike structure. FSF was then conducted to generate the stems and heads of a rivet-like structure from the base material. Joint members can be stacked within the forming limit (i.e. Fig. 3). Figure 10 depicts fabricated joints between aluminum alloy and steel, and CFRP and steel. Advantages of the methodology despite requiring the preparation of holes on the joined member are:

(1) Unlike FSW, there is no metallurgical limitation for a mechanically joined member.

(2) There is no weight increase.

A recyclable 'separable' joint that employs hook-like joints and prepared keyholes can also be generated with a similar technique to the above. See reference [13] for more detail.

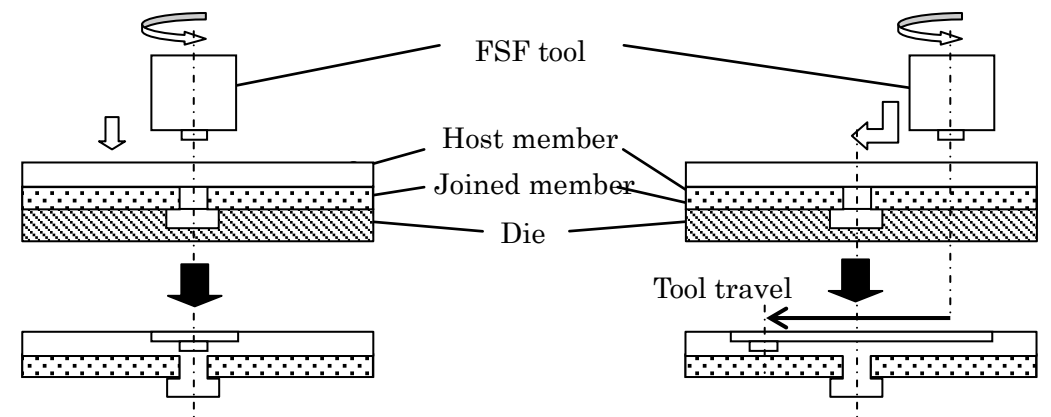

Fig. 9 Schematics of 'fastener-less riveting.' [9].
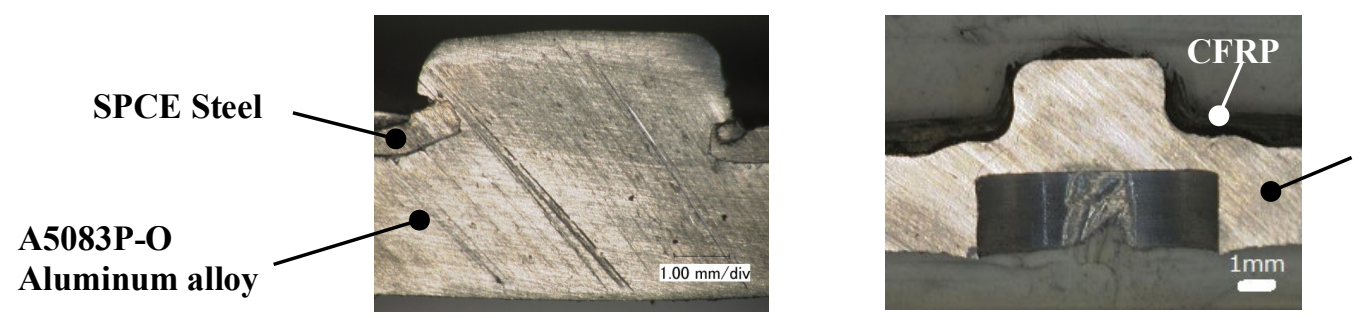

A5083P-O

Aluminum alloy

Fig. 10 Cross-sectional images of the joints of 'fastener-less riveting.' [9].

Joining with Conventional Punching Preprocessing. Figure 11 depicts the schematics of a more sophisticated technique using prepared holes with conventional punching [14]. Generally, conventional punching is conducted with a clearance between the punch and the die. This generates an inclined surface at the wall of a punched hole because of shear droop or the breakout angle. The inclined surface can be used as a source of mechanical interlocking with FSF. Figure 12 shows a cross-sectional image of the fabricated joint between a $3 \mathrm{~mm}$-thick A5083P-O aluminum alloy and a $1 \mathrm{~mm}$-thick SPCE steel sheet. Mechanical interlocking from shear droop was observed. 


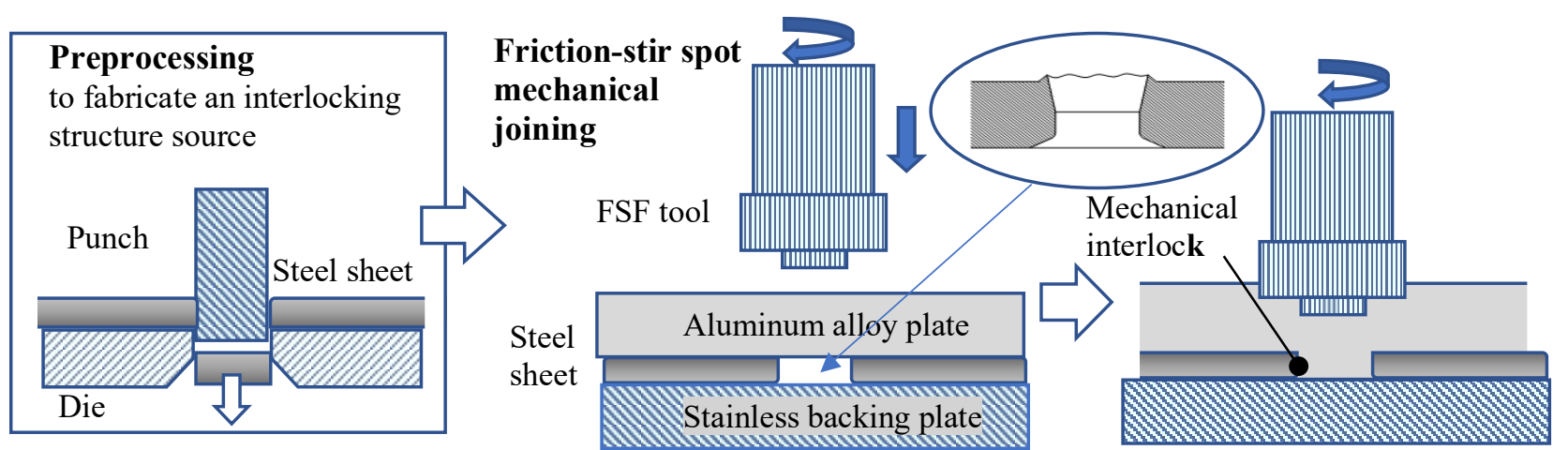

Fig. 11 Schematics of joining with conventional punching preprocessing [14].

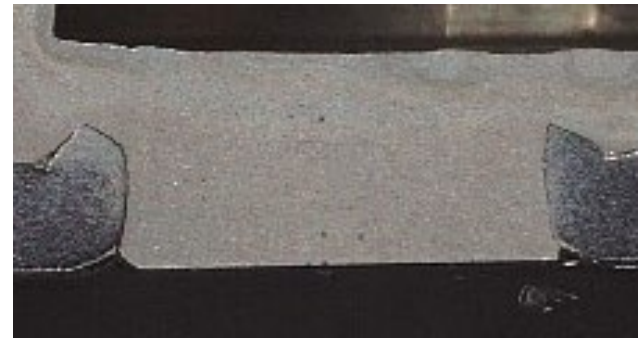

Fig. 12 Cross-sectional images of the joint using the prepared hole with conventional punching.

\section{Summary}

In this paper, we present mechanical joining techniques for dissimilar materials by employing FSF and preprocessing to fabricate a source of mechanical interlocking. The suggested methodology is based on mechanical joining; therefore, process condition restrictions including the selection of joined materials are more permissive than metallurgical joining such as conventional FSW.

\section{Acknowledgment}

The financial support of JSPS KAKENHI 18K03882 and the Amada foundation AF-2019050-X1 is much appreciated.

\section{References}

[1] M.W. Thomas, J. Nicholas, J.C. Needham, M.G. Murch, P. Templesmith, C.J. Dawes, US Patent, 5,460,317. (2001).

[2] K. Ohishi, H. Fujii, Technical Topics and Automobile Applications of Friction Stir Welding, Materia Japan 53-12 (2014) 603-607.

[3] K. Feng, M. Watanabe, S. Kumai, Microstructure and Joint Strength of Friction Stir Spot Welded 6022 Aluminum Alloy Sheets and Plated Steel Sheets, Mater. Trans. 52-7 (2001) 1418-1425.

[4] S. Bozzi, A.L. Helbert-Etter, T. Baudin, B. Criqui, J.G. Kerbiguet, Intermetallic compounds in Al6016/IF-steel friction stir spot-welds, Mater. Sci. Ser. A 527-16/17 (2010) 4505-4509.

[5] Y. Abe, M. Kishimoto, T. Kato, K. Mori, Mechanical Clinching of Hot-Dip Zinc-Aluminum Alloy Coated Steel Sheets, J. Japan Soc. Technol. Plast. 51-593 (2010) 592-596.

[6] W.M. Thomas, Friction stir welding and related friction process characteristics, Proc. 7th International Conference Joints in Aluminium (INALCO’98) (1998) 1-18.

[7]T. Nishihara, Japanese Patent. 4,646,421.(2002).

[8]T. Nishihara, Development of Friction Stir Forming, Mater. Sci. Forum, 426-432 (2003) 29712978. 
[9] T. Ohashi, H. Mofidi-Tabatabaei, T. Nishihara, Fastenerless-Riveting Utilizing Friction Stir Forming for Dissimilar Materials Joining, Key Eng. Mater. 751 (2017) 186-191.

[10] T. Nishihara, Development of Friction Stir Forming, Report on the Results of Grant Research of the Amada Foundation 17 (2004) 50-54.

[11]H. Mofidi-Tabatabaei, T. Nishihara, Friction stir forming for mechanical interlocking of insulated copper wire and Zn-22Al superplastic alloy, Weld. World 61-1(2017) 47-55.

[12] H. Mofidi-Tabatabaei, T. Nishihara, Friction Stir Forming for Mechanical Interlocking of UltraThin Stainless Steel Strands and Aluminum Alloys, Defect and Diffusion Forum 382 (2017) 114119.

[13] T. Ohashi, H. Mofidi-Tabatabaei, T. Nishihara, Mechanical behavior and fracture of easilydecomposable dissimilar-materials joint fabricated by friction stir forming, Mech. Eng. J. 5-2 (2018) $1-9$.

[14] T. Ohashi, H. Mofidi-Tabatabaei, T. Nishihara, Mechanical joining utilizing shear droop in a punched hole with friction stir forming. Submitted to 23rd International Conference on Material Forming (ESAFORM 2020). 